\title{
Derecho Constitucional Comparado
}

\section{Karel Luis Pachot Zambrana}

Universidad de Oriente, Cuba

La comparación jurídica, siguiendo a Giusseppe de Vergottini, supone "la operación intelectual del contraste entre ordenamientos, institutos y normativas de diferentes ordenamientos que, si se lleva a cabo de manera sistemática y según los cánones del método jurídico, asume los caracteres de las disciplinas científicas". Es entonces cuando, madurado el conocimiento y la comprensión científicos, arribamos al método del Derecho comparado, cual una suerte de conductor y traductor de las realidades y contextos jurídicos ajenos - más no extraños - que nos permite entender, definitivamente, los propios.

Esa necesaria comprensión desde la academia jurídica fue tempranamente atendida desde los propios inicios del siglo XX, primero con la celebración en 1900 del Congreso Internacional de Derecho en París, luego con la fundación de los primeros institutos de Derecho comparado en el mundo (el primero de ellos en Argentina en 1939, siguiéndole en México en 1940) y, categóricamente, con la publicación de revistas especializadas (como el inicialmente publicado como Boletín del Instituto de Derecho Comparado desde 1948, y que en 1968 pasó a denominarse Boletín Mexicano de Derecho Comparado, o la Revue internationale de droit comparé, publicada desde 1949).

Precisamente, justificado en la necesidad de separar, en ocasiones, los criterios, métodos y esquemas de los manuales de Derecho constitucional clásico, a los que justipreciaba pero alertando siempre de todas las reservas con que debía apreciarse 1o "clásico" entonces, nos invitaba Manuel García-Pelayo a estudiar su - ya "clásico" entre nosotros - manual de Derecho constitucional comparado. Con ello nos legó una de las más valiosas obras que han trascendido el estudio y comprensión del Derecho constitucional contemporáneo más allá de cualquier

1 Giusseppe de Vergottini, "Balance y perspectivas del Derecho constitucional comparado", en Revista Española de Derecho Constitucional, Año 7, Núm. 9, Enero-Abril 1987, p. 166. 
contexto geopolítico, histórico o ideológico. Precisamente soportado todo ello en el Derecho comparado.

En cierta medida, honor a todo ello rinde este novedoso y magnífico manual de estudio del Derecho constitucional contemporáneo, en una edición ampliada y actualizada de aquel que podemos considerar su primera edición lograda en el año 2000 (y cuyo título entonces fue Nuevo Derecho constitucional comparado, conducido por los mismos directores y publicado por la propia Editorial Tirant Lo Blanch). La excelencia en los resultados ofrecidos para la academia jurídica de esta obra se evidencian por la labor profundamente seria y responsable de prestigiosos profesores españoles e italianos, codirigidos por Diego López Garrido y Marcos Francisco Massó Garrote, Catedráticos de Derecho Constitucional de la Universidad de Castilla La Mancha (España) y Lucio Pegoraro, Catedrático de Derecho público comparado de la Universidad de Bolonia (Italia). Este último todo un referente mundial en la reivindicación de los estudios comparados en el Derecho, cual Quijote contemporáneo perfectamente ubicable en cualquier lugar del planeta.

Y ello es verificable a propósito de la casi absoluta ausencia del método de Derecho comparado en los estudios encargados de la formación profesional de los juristas en la actualidad (tanto en el grado o la licenciatura como en el posgrado). Frente a esta cuestionable realidad se posiciona, aportando novedosas interpretaciones y formulaciones dogmáticas, enriquecidas por las experiencias personales de sus autores, la obra Derecho constitucional comparado. Todo ello se logra con una loable claridad y sencillez expositiva, pero con un elevado rigor y, mucho más, una inequívoca lucidez intelectual cuando se explican las problemáticas que pueden derivarse de la regulación de cualquier institución constitucional en los ordenamientos jurídicos abordados.

La obra se inicia, en su contenido, con una introducción metodológica imprescindible para todo este tipo de libros, y donde se expone brevemente el aparato conceptual o categorial básico del Derecho comparado: su definición, rasgos históricos, objeto, relación con otros saberes del Derecho y, como necesariamente debe ser, de otras ciencias sociales e, incluso, humanísticas. 
Luego se exponen, estructurados en tres partes fundamentales (Derecho y sociedad, Derecho y Estado y, finalmente, Garantías constitucionales y protección de la Constitución), las principales instituciones que interesan a todo Derecho constitucional en la contemporaneidad, ahondados desde las perspectivas que brinda el estudio comparativo, identificando singularidades y diferencias, pero más allá de ellos, revelando las tendencias más actuales.

Uno de los aportes más valiosos de la obra lo constituye la enjundiosa bibliografía básica expuesta al inicio de la misma, clasificada en obras generales de Derecho comparado, manuales de Derecho público o constitucional comparado, manuales metodológicos de Derecho público comparado o constitucional, revistas y enciclopedias y diccionarios enciclopédicos. En ellos encontrarán los lectores, sino todo, parte de lo más valiosamente producido en torno al método comparativo en el Derecho y que constituyen referencias obligadas para todo estudio que posteriormente nos planteemos desde cualquier rama jurídica, me atrevo a afirmar. Incluso, cada aportación de la obra culmina con las referencias bibliográficas sistematizadas según las instituciones que se estudian en cada una de ellas.

Esta obra, que constituye ya en la actualidad una referencia ineludible en el ámbito académico del Derecho constitucional, principalmente en Iberoamérica, nos propone superar definitivamente el eurocentrismo anquilosado históricamente. Al abordar las experiencias nacionales no sólo de Europa, sino de las Américas (con énfasis en la América Latina), Asia y África, siguiendo las coordenadas brindadas por el neoconstitucionalismo posterior a la Segunda Guerra Mundial (de ahí estudio obligado en la tercera de sus partes, Garantías constitucionales y protección de la Constitución), queda evidenciada la necesidad de comprender la globalización contemporánea no sólo en el ámbito económico sino, y principalmente, en el ámbito jurídico (que es más bien ideológico, filosófico o cultural).

$\mathrm{Y}$, precisamente, en ello radica quizás la mayor trascendencia de esta obra, partiendo de sus precedentes. Apreciar, observar, comprender y criticar oportunamente ya no solo el Derecho europeo, sino todo el Derecho 
que globalmente ofrece el mundo, consolidará y satisfacerá, estoy seguro, no sólo a los estudiosos del Derecho constitucional sino a todos los juristas que invariablemente aspiren a la mejor de las formaciones profesionales.

\section{Bibliografía}

Libro: Derecho Constitucional Comparado

Directores: Diego López Garrido, Marcos Francisco Massó Garrote y Lucio Pegoraro

Autores: Diego López Garrido, Marcos Francisco Massó Garrote, Lucio Pegoraro, Tomás Bastarreche, Roberto Blanco Valdés, José Luis García Guerrero, Juan Fernando López Aguilar, María Luz Martínez Alarcón, José María Morales Arroyo, Angelo Rinella y Gerardo Ruiz-Rico Ruiz.

Editorial: Tirant Lo Blanch

Lugar: Valencia, España

Año: 2017 